\title{
Porto de Santos: o surgimento da cultura de resistência à globalização
}

Katherine Realle Nóbrega de Andrade Publicitária, especialista em Gestão da Comunicação e analista de Comunicação Pleno da empresa Santos Brasil S/A.

E-mail: karealle@gmail.com

Resumo: O presente estudo tem o objetivo de investigar as relações de trabalho no Porto de Santos, localizado na Baixada Santista, litoral de São Paulo. O Porto e a cidade de Santos, ao longo da história, passaram por inúmeras transformações econômicas e sociais que influenciaram fortemente as relações de trabalho. A partir do conflito entre comerciantes e trabaIhadores locais, surgiu a cultura portuária que tenta, até os dias atuais, preservar suas raízes mediante uma nova cultura disseminada pelo empresariado.

Palavras-chaves: comunicação, Santos, Porto, cultura de resistência, memória, movimento operário.
Abstract: The present study has the objective to investigate the working relationships in the Port of Santos, located at Baixada Santista, in the coast of São Paulo. The Port and the city of Santos, along history, have gone through many social and economical transformations that have strongly influenced the working relationships. As from the conflict between small business owners and local workers that the port culture has arisen, which, from them to the present days, tries to preserve its roots upon a new culture spread by the company owners.

Keywords: comunication, Santos, Port, culture resistance, memory, portworkers' mobilization.

Muitos pesquisadores têm investigado o desenvolvimento dos portos como um espaço de produtividade, abertura de economias e políticas entre nações. Nesses espaços de alta produção convivem milhares de trabalhadores, como os que participaram do nascimento do maior porto da América do Sul: o Porto de Santos. A seguir, relato neste artigo o desenvolvimento da pesquisa e do projeto de Gestão da Comunicação que apresentei aos docentes do Departamento de Comunicação e Artes da Universidade de São Paulo, para a obtenção do título de especialista em Gestão da Comunicação. Um enfoque humano sobre o porto empresarial foi a proposta deste trabalho. A partir do resgate histórico, o projeto de Gestão em Comunicação propõe uma articulação de conceitos e ideias sobre a cultura de resistência num estudo voltado para a valorização dos trabalhadores portuários da cidade de Santos. 
comunicação \& educação • Ano XV • Número 1 • jan/abr 2010

\section{O GRANDE PORTO}

O Porto de Santos, hoje, é sinônimo de eficiência, modernidade e agilidade. Trabalhar no Porto é ver nitidamente tudo o que entra e sai no País; é ver um contêiner e imaginar em quais países ele já esteve, quantas pessoas já o transportaram, ou seja, é perceber a transitoriedade das mercadorias, das pessoas, enfim, a passagem da história.

Esse chão que abriga milhares de trabalhadores já sustentou escravos, estivadores, presidentes e autoridades dos mais diversos países. O intuito deste trabalho não é analisar o Porto somente pelo seu aspecto econômico, mas percebê-lo como um local de passagens, conflitos, políticas e mudanças.

A relação cidade portuária, estado e país é marcada por sucessivas modernizações ao longo da história. De fato, foi a produção cafeeira que permitiu o crescimento de Santos e intensificou suas relações econômicas com as demais regiões do País. A modernização do final do século XIX elevou o Porto à condição de porto organizado, porém gerou transtornos entre os trabalhadores e a Companhia Docas de Santos que gerenciava o trabalho no porto.

Além das atividades econômicas, o Porto reordenou a cidade através de novos espaços urbanos e saneamento. Foi através do Porto que Santos ganhou sua autonomia e estreitamento econômico com a região paulista. Embora a cidade tenha surgido antes, tornou-se coadjuvante no processo de desenvolvimento do País.

\section{COMUNICAÇÃO AUTORITÁRIA E SEM TRANSPARÊNCIA}

O problema da comunicação de muitas empresas do Porto de Santos está entrelaçado à mistura das culturas empresarial e portuária que se confrontam na junção do presente ao passado. Muitos trabalhadores ainda estão presos às raízes portuárias que cultivam os movimentos trabalhistas, a cultura estatal e, em algumas situações, o conformismo.

A automação, a reengenharia, a terceirização e a competição movimentam o pensamento neoliberal que está direcionado às novas formas de gestão, aos programas de qualidade total e às certificações. A linguagem, hoje utilizada pelas empresas, foge do campo de compreensão dos trabalhadores que ainda visualizam seus interesses como os únicos a serem seguidos.

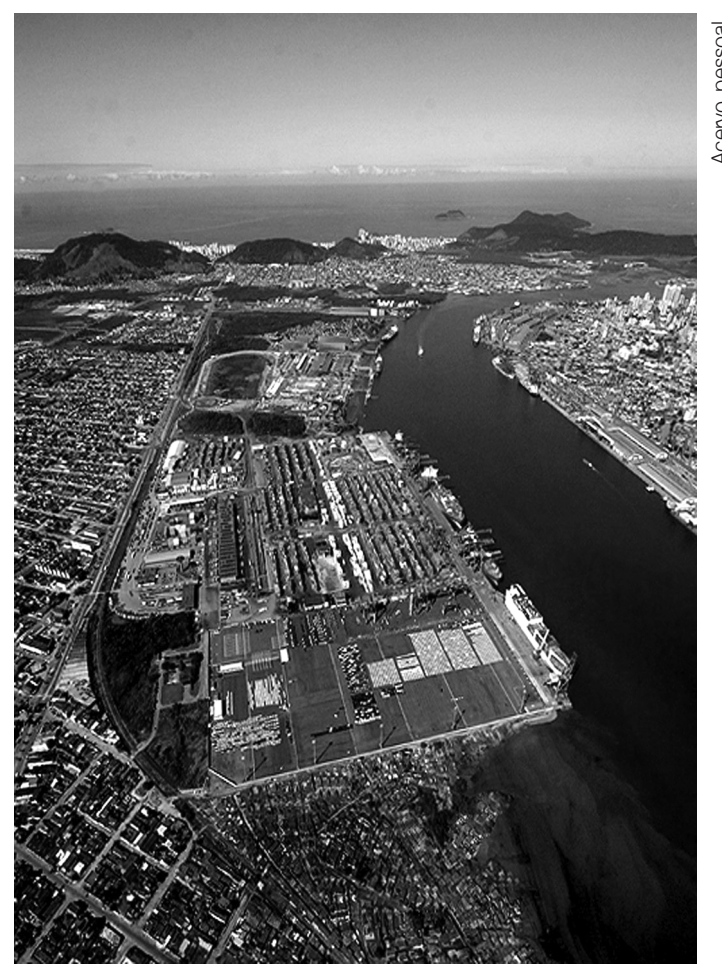

Vis o a rea do Porto de Santos: em busca da agilidade na transitoriedade das mercadorias e informações. 
A comunicação no trabalho portuário precisa ter uma lógica ligada aos trabalhadores e não somente à produtividade. Mais do que nunca, a transparência se faz necessária para que os funcionários percebam o porquê das mudanças e como elas estão acontecendo.

Diante desse conflito, cabe ao comunicador elaborar propostas de políticas internas, o que o obriga: a conhecer os agentes sociais envolvidos e a identidade cultural daquele espaço; reunir a prática com as teorias e desenvolver novas perspectivas comunicacionais; gerenciar e planejar os processos comunicativos; fazer diagnósticos e assessorar a alta administração nesse conflito interno que prejudica as relações de trabalho e a aderência aos programas da companhia. "Esse profissional Comunicador é aquele capaz de cumprir seu papel de mediador, utilizando-se com o mesmo peso, da sensibilidade e da técnica."

\section{UMA BREVE ABORDAGEM DA CULTURA DE RESISTÊNCIA}

Para fundamentar o estudo que ora relatamos, foram selecionados alguns autores que discorrem sobre a cultura de resistência e a comunicação moderna. Ao longo deste artigo, existem várias citações de autores que argumentam e discutem os temas de cultura, trabalho e comunicação.

A resistência pode ser definida como a oposição a um sistema de forças ou a capacidade de lutar em defesa de algo e de fazer frente aos mecanismos de repressão em que se enfrente uma luta ideológica.

Com base nas discussões sobre o tema, destaca-se o pensamento de Marilena Chauí ${ }^{2}$, que adota uma definição de cultura popular como elemento que age no íntimo da cultura dominante, refutando-a ou não. Por motivos ideológicos, Marilena centra sua análise nas manifestações que existem em função da cultura dominante, seja assimilando-a numa atitude conformista, seja recusando-a através de atitudes de resistência. Assim, sua análise afirma que a camada popular não cria ou experimenta nada independentemente da cultura dominante. Suas práticas e vivências culturais surgem das relações de conformismo e resistência, sem considerar outras relações possíveis como a troca ou a influência do popular sobre o dominante.

Os ideais de Marilena Chaú estão muito próximos aos conceitos de Antonio Gramsci, que discute a elaboração da cultura na classe dominante, penetrado por divergências nas camadas inferiores, vendo o movimento em um único sentido. Na busca de um espaço de contradominação, propõe-se a elaboração de uma cultura alternativa enraizada à cultura da classe operária, que representa uma radical ruptura, entrando em choque com a cultura dominante.

Já o antropólogo Denys Cuche ${ }^{3}$ afirma que o fraco valor da noção de cultura levou pesquisadores a reconsiderar o conceito de cultura e subcultura de classe, baseando-se nas tradições marxistas. Estudos mostraram que os modelos de comportamento variam de uma classe para outra, e estas diferenças podem ser observadas no cotidiano, principalmente nos grupos encontrados dentro das organizações.
1. BACCEGA. Maria Aparecida. Gestão de Processos Comunicacionais: uma experiência de 10 anos. In: FíGARO, Roseli (Org.) Gestão da Comunicação no mundo do trabalho, educação, terceiro setor e cooperativismo. São Paulo: Atlas, 2005. p. 14

2. CHAUÍ, Marilena. Conformismo e resistência. São Paulo: Brasiliense, 1996.

3. CUCHE, Denys. A noção de cultura nas Ciências Sociais. Bauru: Editora Edusc, 1999. 
Cuche complementa a análise da relação empresariado x classe operária quando cita Max Weber e seu estudo sobre o surgimento dos empresários capitalitas. Em A ética protestante e o espírito do capitalismo, publicado em 1905, ele tenta demonstrar o comportamento do empresariado e seu sistema de valores, totalmente opostos às classes operárias. Segundo Cuche, muitas pesquisas francesas contribuíram para o entendimento da classe operária que priorizava os bens de utilidade pública e o reforço da solidariedade familiar. Para ele, já não existem mais comunidades operárias agrupadas no mesmo bairro. O particularismo cultural operário tornou-se menos visível.

Clifford Geertz ${ }^{4}$ complementa esse quadro com a realização de uma análise antropológica das dimensões culturais da política, da religião e dos costumes sociais. Nesses estudos, percebeu a cultura como estrutura de organização das sociedades, que pode ser definida como um sistema de ordenação e controle das coletividades pautado em um mecanismo de apreensão do poder e da submissão dos membros de uma comunidade política. Segundo o autor, na Antropologia o conceito de cultura passa a ser visto como um padrão de significados transmitidos historicamente, incorporado em símbolos e materializado em comportamentos.

Hoje, nas empresas do segmento portuário, as formas de comunicação e as mudanças culturais são claramente influenciadas pelo capitalismo, desfavorecendo o relacionamento entre empresários e trabalhadores. Raramente as organizações propõem formas interativas de diálogo entre os grupos da empresa. Por esse motivo, conflitos ideológicos e trabalhistas são encontrados no mundo do trabalho como grandes desafios das áreas de comunicação.

\section{PESQUISA DE CAMPO}

Para compreender o problema, foi realizada uma pesquisa com formadores de opinião de uma das maiores operadoras portuárias do País. O objetivo da pesquisa era ouvir os trabalhadores sobre as temáticas: relações de trabalho, hábitos diários e utilização dos meios de comunicação da empresa. Os trabalhadores selecionados possuem grande experiência de trabalho no Por-

4. GEERTZ, Clifford. A interpretação das culturas. Rio de Janeiro: Editora Ltc, 1989.

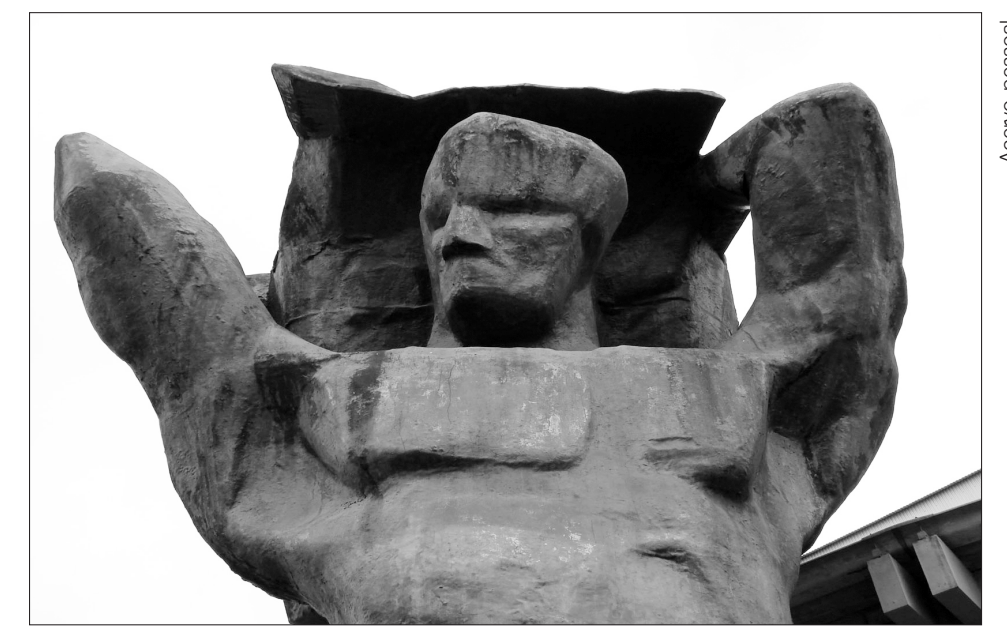

Imagem do trabalhador portuário, passando a influenciar sua rede de relações e conquistar seu pr prio espa 0. 
maior área da empresa: Operações. A amostra por significância abrangeu 20 pessoas e a coleta de dados foi realizada mediante questionário, entrevista e conversas informais para captar melhor as reações e as expressões dos avaliados.

Ao relatar suas experiências e opiniões, os trabalhadores reafirmam o orgulho que têm de trabalhar no Porto de Santos, o maior da América do Sul; no entanto, mostram-se decepcionados com a distância que se criou diante das novas perspectivas e formas de gestão. Além disso, foi comentado que as empresas não aproveitam seus talentos, preferindo contratar pessoas jovens pouco experientes para funções que poderiam ser ocupadas pelos funcionários atuais. As inovações são vistas com satisfação, mas também com resistência. O medo do desconhecido fica evidente entre os entrevistados. Segundo eles, as novas tecnologias geram mais vontade de aprender e estudar. Esse novo perfil é uma novidade na cultura portuária, pois os próprios trabalhadores estão buscando qualificação e percebendo que o crescimento profissional está atrelado à educação. Antes o saber era algo proveniente da prática; hoje, os trabalhadores complementam essa afirmação com a graduação. Muitos estão preocupados com a continuidade do Ensino Médio, planejando cursar uma faculdade.

Os entrevistados apontam a falta de transparência das empresas e que os programas são impostos aos trabalhadores, sem explicações. Essa ausência de diálogo ocorre, também, segundo eles, entre chefes e subordinados. Muitos comentaram, fora das entrevistas, que não se sentem confortáveis nem ouvidos pelos seus líderes.

Cabe ressaltar que através da pesquisa foi possível perceber que os trabalhadores vivem um conflito por não compreenderem a mudança na forma de trabalho do Porto. Os modos de gestão, os indicadores e as metas, cada vez mais ousadas, são padrões desconhecidos para os trabalhadores, principalmente os operacionais.

A autoestima profissional dos entrevistados apresenta-se, aparentemente, baixa. Muitos afirmam que se sentem mais um número de crachá e que não enxergam perspectiva de crescimento dentro da empresa. Parte desse descontentamento estava relacionado à falta de políticas e regras claras, a superiores ausentes e salário defasado.

Nas relações de trabalho, foi destacada a amizade entre os colegas de trabalho e a dificuldade de interação com as chefias. Trabalhadores do mesmo nível hierárquico não enfrentam tantos problemas, mas na relação chefe e subordinado há um desgaste atribuído à falta de comunicação e respeito.

Mesmo com todos os problemas, os trabalhadores revelaram grande orgulho de fazer parte da família portuária e contam várias histórias de suas famílias que também trabalharam no Porto de Santos.

\section{UMA QUESTÃO DE INTERLOCUÇÃO}

Diante dos problemas apontados na pesquisa, o projeto de Gestão da Comunicação tem o intuito de aproximar os funcionários e as empresas, ou seja, 
diminuir o problema de interlocução entre o empresariado e os trabalhadores que ainda trazem conceitos e memórias do sistema estatal.

A base deste projeto é o resgate da memória portuária. Muitos entrevistados expuseram que não se sentem pertencentes às empresas onde trabalham ao passo que as companhias crescem. Além disso, o foco nos novos projetos e nas tecnologias ofuscou a figura do trabalhador, outrora valorizada. Através da peculiar linguagem portuária, de momentos históricos e depoimentos vivenciados durante o trabalho no Porto, acreditamos ser possível retomar a participação dos funcionários nos futuros projetos da companhia.

A memória diz respeito a algo que não podemos modificar, pois pertence ao passado. No entanto, ela é imprescindível para conhecer, preservar e determinar nossa relação com o mundo e escrever nossa própria história. Longe de tratar a memória como um conjunto de saberes acumulados, esse projeto propõe a reflexão sobre diferentes aspectos presentes na relação entre o Porto e os trabalhadores. Essa afinidade envolve suas significações e suas contradições, a construção política e histórica do Porto, os impasses criados pela tecnologia e as políticas comerciais como objeto de poder.

Embora se diga que as mídias, particularmente a internet, estão ao alcance de todos, sua utilização exige um paciente diálogo entre a nova tecnologia e a cultura da empresa que pretende adotá-la. Especificamente nos terminais portuários, há uma grande preocupação em fazer com que os trabalhadores adquiram familiaridade com o meio tecnológico, uma vez que os novos equipamentos, cada vez mais, utilizam sistemas digitais para seu funcionamento.

A primeira proposta do projeto de gestão é a construção de um site, chamado Um Porto de memórias, que funcionará como um banco virtual de informações históricas, alimentado pelos próprios funcionários das empresas portuárias. A inserção de acontecimentos históricos, fotos e depoimentos recontará a história do Porto aos olhos de quem os construiu e participou do seu desenvolvimento. A intenção dessa ferramenta virtual é servir como fonte de pesquisa a todos aqueles interessados no tema: funcionários, estudantes, pesquisadores e a população em geral.

Numa segunda etapa, após reunir uma grande quantidade de informações sobre o Porto, os dados serão compilados e uma editora será contratada para confeccionar o livro de memórias que será disponibilizado aos trabalhadores locais. Esse livro conterá as histórias do Porto, depoimentos, fotos do trabalho portuário e das famílias que já passaram pelo cais santista.

A terceira etapa do projeto prevê a realização de fóruns para discussão dos assuntos atuais da área portuária. O objetivo dos fóruns é estimular os funcionários das empresas ao debate sobre assuntos que realmente pertençam à realidade do trabalho. É imprescindível que o empresariado estruture seus projetos coletando sugestões e ideias dos trabalhadores, pois eles atuam no dia a dia dos problemas e vivenciam o mecanismo do Porto. Os benefícios serão mútuos, pois os empresários receberão mais ideias para fomentar os projetos e os trabalhadores sentir-se-ão pertencentes à cadeia de trabalho. 
A proposta é que os fóruns ocorram em tendas armadas no Porto, com toda a infraestrutura necessária para acomodar os trabalhadores. Os encontros terão frequência trimestral, com temas que abranjam os problemas do mercado e da mão de obra.

\section{UMA LUTA SEM FIM}

A partir das manifestações socioespaciais decorrentes do processo de modernização de Santos foi possível entender o desenvolvimento das relações trabalhistas no Porto. No decorrer da pesquisa, observou-se o descontentamento dos trabalhadores em relação à falta de transparência e à valorização excessiva da tecnologia.

A cultura de resistência está projetada no Porto de Santos, desde o seu início, devido às más condições de trabalho e higiene. Ao longo dos anos, essa cultura foi sedimentada pelos sindicatos, pelas associações e até mesmo por artistas. $\mathrm{O}$ aumento dos grupos e movimentos sindicais fomentou a livre expressão dos trabalhadores e os ideais anarco-sindicalistas proliferaram através dos jornais locais.

Pode-se afirmar, então, que a cultura de resistência no Porto é resultado das manifestações da mídia local, dos grupos sindicais e de uma gama de trabalhadores, imigrantes e regionais, que buscavam a melhoria do trabalho, a igualdade dos direitos e a satisfação da comunidade.

Todas as lutas e reivindicações têm o intuito de beneficiar o grupo de trabalhadores, que se vê como uma família. A abertura de capitais, a chegada de novos equipamentos e a expansão da infraestrutura portuária tornou o trabalhador alheio ao próprio trabalho. Sem compreender a real mudança política do Porto, esse trabalhador não consegue perceber o seu papel dentro da cadeia produtiva e sua real importância; logo, o sentido do trabalho se perdeu em meio às novas formas de gestão.

Os trabalhadores necessitam estar mais próximos da empresa. Para isso, o Projeto de Gestão propõe uma nova forma de interlocução que reveja a linguagem e os novos espaços interativos.

Com a ampliação do contato empresa e funcionário, espera-se que o clima de tensão e a não aderência aos projetos diminuam ao longo do tempo, uma vez que os trabalhadores começarão a ter informações sobre a realidade da empresa, e passarão de participantes para agentes do processo de trabalho. Tornando-se ativos, eles sentir-se-ão parte integrante da produção e seu real valor será refletido através de suas ações.

Para o gestor de processos comunicacionais, conhecer a dimensão cultural, o modo de vida e as relações de trabalho é imprescindível para mediar os lugares da intervenção, integrar pessoas, resgatar a memória e dar continuidade às histórias do mundo do trabalho. O cotidiano pode ser efêmero, mas também pode ser um espaço interativo e de complementaridade, desde que as partes envolvidas tenham um olhar mais democrático e sem interesses exclusivamente de poder. 
comunicação \& educação • Ano XV • Número 1 • jan/abr 2010

\section{REFERÊNCIAS BIBLIOGRÁFICAS}

ANDRADE, Wilma Therezinha Fernandes de. O discurso do progresso: a evolução urbana de Santos, 1870-1930. Tese de doutorado apresentada à Faculdade de Filosofia, Letras e Ciências Humanas da Universidade de São Paulo, 1989.

ANTUNES, Ricardo. Adeus ao trabalho? Ensaio sobre as metamorfoses e a centralidade do mundo do trabalho. São Paulo: Cortez, 1998.

ARAÚJO FILHO, José Ribeiro de. Santos, o Porto do café. Rio de Janeiro: Fundação IBGE/Instituto Brasileiro de Geografia, 1969.

BACCEGA, Maria Aparecida. Gestão de Processos Comunicacionais: uma experiência de 10 anos. In: FÍGARO, Roseli (Org.). Gestão da Comunicação no mundo do trabalho, educação, terceiro setor e cooperativismo. São Paulo: Atlas, 2005.

CARONE, Edgard. Classes sociais e movimento operário. São Paulo: Ática, 1989. CHAUÍ, Marilena. Conformismo e resistência. São Paulo: Brasiliense, 1996.

COSTA, Maria Cristina Castilho. Educação, imagem e mídias. São Paulo: Cortez, 2005. . Ficção, comunicação e mídias. São Paulo: Senac, 2002.

\section{8.}

Sociologia: introdução à Ciência da Sociedade. São Paulo: Moderna,

CUCHE, Denys. A noção de cultura nas Ciências Sociais. Bauru: Editora Edusc, 1999.

GEERTZ, Clifford. A interpretação das culturas. Rio de Janeiro: Editora Ltc, 1989.

GITAHY, Maria L. Caira. Ventos do mar. São Paulo: Editora Unesp, 1992.

GONÇALVES, Alcindo; NUNES, Luiz Antonio de Paula. O grande Porto. Santos: Realejo, 2007.

HABERMAS, Jürgen. O discurso filosófico da modernidade. Lisboa: Dom Quixote, 1990.

LANNA, Ana Lúcia Duarte. Uma cidade na transição - Santos: 1870 a 1913. São Paulo: Hucitec, 1996.

PAULINO, Roseli A. Fígaro. Relações de comunicação no mundo do trabalho. São Paulo: Annablume, 2008.

. Comunicação e trabalho. São Paulo: Anita, 2001.

PEREIRA DA SILVA, Moacir. Centenário do Porto de Santos. Santos: Publisan Publicidade de Santos Ltda., 1992.

RUEDA, Waldir. Brás Cubas. Santos: Editora Comunicar, 2007.

SANTOS, Francisco Martins dos. História de Santos. São Vicente: Caudex, 1986.

WEBER, Max. A ética protestante e o espírito do capitalismo. São Paulo: Companhia das Letras, 2004. 